\title{
Efeitos do peso vivo sobre a comercialização de bezerros de corte em leilões
}

[Effects of the live weight on the commercialization of beef calves in auction barn]

\author{
L.F. Christofari ${ }^{1}$, J.O.J. Barcellos ${ }^{2,6^{*}}$, J. Braccini Neto ${ }^{2}$, R.P. Oaigen ${ }^{3}$, A.P. Santos ${ }^{4}$, M.E.A. Canozzi ${ }^{5}$ \\ ${ }^{1}$ Universidade Federal de Santa Maria - CESNOR - Palmeiras das Missões, RS \\ ${ }^{2}$ Departamento de Zootecnia - NESPRO-UFRGS \\ Av. Bento Gonçalves, 7712 \\ 91540-000 - Porto Alegre, RS \\ ${ }^{3}$ Universidade Federal do Pará - Castanhal, PA \\ ${ }^{4}$ Universidade Federal do Pampa - Dom Pedrito, RS \\ ${ }^{5}$ Aluna de pós-graduação - NESPRO-UFRGS (Bolsista CAPES) \\ ${ }^{6}$ Pesquisador do $\mathrm{CNPq}$
}

\begin{abstract}
RESUMO
Analisaram-se os efeitos da média de peso vivo de 1.880 lotes de bezerros comercializados em 13 leilões, no Rio Grande do Sul, sobre o valor de venda final por unidade de peso, e caracterizou-se a frequência dos lotes conforme a classe de peso durante as estações de outono e primavera, no período de 2004 a 2006. Os dados foram corrigidos pelo índice geral de preços - disponibilidade interna e analisados por meio de histogramas de frequência e análises de regressão e correlação. O peso vivo influenciou o preço dos bezerros, e a magnitude do efeito foi maior nos anos de grande demanda. Observou-se correlação negativa entre preço e peso dos bezerros na primavera, reflexo da oferta de animais mais pesados, devido aos efeitos de estação do ano ou à maior idade dos bezerros, comparados aos ofertados no outono. Não se observou maior liquidez dos bezerros comercializados no outono em relação aos da primavera. A conjuntura da cadeia da carne bovina e os preços de outras categorias têm grande relação com os preços pagos. A aquisição de animais de menor ou maior peso na ocasião da transação comercial pode auxiliar na redução dos custos que a reposição representa na produção.
\end{abstract}

Palavras-chave: bovino de corte, gestão rural, pecuária de cria, sistemas de produção

\begin{abstract}
The effects of the live weight of 1,880 lots of calves marketed in 13 auctions in the State of Rio Grande do Sul, Brazil, on the value of final sale per unit of weight were evaluated, as well as the frequency of the lots according to the weight class during the autumn and spring seasons, in the period from 2004 to 2006 , was characterized. The data were analyzed by frequency histograms, regression, and correlation analyses. The live weight is one of the characteristics that influenced the price of the calves; however, the magnitude of the effect was higher in years of great demand. A negative correlation was observed between price and weight of the calves in spring, which were results of the offer of heavier animals, due to the season effects or the oldest age of the calves compared to those presented in the autumn. The chain conjuncture of the bovine meat and the prices of other categories have great relation with the prices paid. Therefore, the acquisition of highter or heavier animals in the occasion of the business deal may help in the reduction of the costs represented by the replacement in the production.
\end{abstract}

Keywords: beef cattle, agricultural management, cow-calf, production system

Recebido em 11 de setembro de 2009

Aceito em 31 de março de 2010

*Autor para correspondência (corresponding author)

E-mail: Julio.barcellos@ufrgs.br 


\section{Christofari et al.}

\section{INTRODUÇÃO}

A lucratividade da pecuária de cria depende primariamente da taxa de desmame, do peso dos bezerros desmamados, dos custos de produção e do preço recebido pelos bezerros e vacas de descarte.

O preço sinaliza o nível de demanda de um produto (Megido e Xavier, 1998; McKissick e Brown, 2001), direciona e coordena a economia de mercado e, de maneira geral, representa o equilíbrio competitivo entre a oferta e a demanda do produto consumido (Eaton e Eaton, 1999). Entretanto, esse equilíbrio não é estático, e a relação ajusta-se aos acréscimos e decréscimos da oferta por meio do preço (Barros, 1987), estimulando a produção com preços altos e desestimulando-a com preços baixos.

As atividades agropecuárias, de forma geral, obtêm receitas em algumas épocas do ano (safra), e as despesas, na grande maioria, distribuem-se ao longo do ano (Reis, 1999). A maior parte das receitas é resultado do preço de venda dos produtos e da escala de produção, sendo o primeiro determinado pelo mercado onde os produtos são comercializados. O produtor tem maior influência sobre o preço quanto menor for a concorrência existente (Marques e Aguiar, 1993), ou seja, quando há pouca oferta e alta demanda, o produtor tem menor concorrência para comercializar seu produto, portanto tem maior poder na negociação do que o comprador, em comparação com cenários inversos na relação de oferta e demanda. Além disso, na pecuária de cria, o preço do bezerro pode ser influenciado pelo valor de outras categorias animais, pois constituem a mesma cadeia produtiva. Do mesmo modo, o destino de áreas ocupadas com a cria para alguns cultivos agrícolas também influencia a formação dos preços.

Independente do sistema de produção adotado, o uso de informações e o conhecimento do mercado podem ter importante efeito no resultado do negócio. No mercado de bezerros, pela falta de uniformidade do produto, especialmente pelos diferentes pesos na apresentação do bezerro por ocasião de venda, tem-se observado grande variação nos preços praticados entre um ou outro tipo de animal. Quando os recriadores e terminadores exercem sua preferência, por meio de diferentes preços de compra dos animais, podem apontar para futuros cenários da pecuária de corte, pois os períodos de alta ou baixa na remuneração dos bezerros determinam a influência no futuro da atividade de cria, caracterizando o ciclo de produção.

A comercialização é um processo social que envolve interações entre agentes econômicos por meio de instituições apropriadas (Barros, 1987). No Sul do Brasil, a comercialização de bezerros geralmente ocorre por meio de vendas diretas entre produtores ou leilões, em que se reunem compradores que disputam entre si, a cada lance, a aquisição do lote desejado.

Os leilões realizados são geralmente coordenados pelas associações de criadores, órgãos do governo estadual ou empresas privadas que organizam a comercialização. Em cada leilão, em geral regionais, ofertam-se de 400 a 3000 bezerros, oriundos de diversos produtores. Estes apresentam seus bezerros em lotes de 10 a 40 animais, conforme a raça, peso vivo, idade, tamanho e condição corporal. No local, os lotes de bezerros são apresentados em pequenos currais, contendo os dados de identificação do proprietário e os dos animais, o que permite uma observação prévia por parte dos compradores. Após isto, os lotes de animais entram em pista para serem comercializados mediante oferta e venda pelo maior lance de oferta (Santos et al., 2006).

A grande vantagem dos leilões é a competição entre os compradores, que é usada para criar mercados, em casos de baixa demanda, ou melhorar os preços, em situações de alta demanda (Meyer, 1997). Além disso, não há a necessidade de conhecimento prévio do mercado, e o preço é estabelecido no momento da comercialização, resultado do equilíbrio entre a oferta (criadores) e a demanda (terminadores) (McKissick e Brown, 2001; Popp e Parsch, 1998).

Este trabalho teve o objetivo de avaliar a influência da média de peso vivo de lotes de bezerros no preço final por unidade de peso, e a oferta existente de acordo com faixas de peso pré-estabelecidas, ao longo de três anos de avaliação, nas estações de comercialização de outono e primavera. 


\section{MATERIAL E MÉTODOS}

Foram analisados dados de comercialização de 30.213 bezerros, distribuídos em 1.880 lotes, em 13 leilões municipais nos anos 2004, 2005 e 2006, durante as estações de outono e primavera.

A pesagem dos animais foi realizada pelas instituições responsáveis pela organização dos leilões e disponibilizada como média de peso de cada lote. O processo de comercialização foi acompanhado durante o leilão de cada lote, quando foram reunidas informações sobre o preço inicial, o preço final, o preço por quilograma de peso vivo, o número de lances e a efetivação da comercialização.

Após a coleta, os dados foram agrupados em planilhas do Microsoft Excel ${ }^{\circledR}$, onde foi realizada a análise exploratória dos dados, determinando a frequência dos lotes ofertados e comercializados em nove faixas de peso vivo, a saber: menor que $130 \mathrm{~kg}, 131$ a $160 \mathrm{~kg}, 161$ a $180 \mathrm{~kg}, 181$ a $200 \mathrm{~kg}$, 201 a $220 \mathrm{~kg}, 221$ a $240 \mathrm{~kg}, 241$ a $270 \mathrm{~kg}, 271$ a $300 \mathrm{~kg}$ e acima de $300 \mathrm{~kg}$. Por meio da relação entre o número de lotes ofertados e os comercializados, foi possível obter a liquidez dos animais nos períodos avaliados. Os preços obtidos pelos lotes foram atualizados pelo índice geral de preços - disponibilidade interna (IGPDI) para $1^{\circ}$ de junho de 2008 obtidos pela FEE (Fundação..., 2008).

Para avaliar o efeito do peso vivo médio do lote no preço por unidade de peso vivo, foi atribuída a denominação $\beta$, para cada 30 quilogramas de peso vivo. Foram realizadas análises da variância, de regressão e correlação dentro dos três anos e nos dois períodos (outono e primavera), utilizando-se os procedimentos GLM, REG e CORR do Software SAS/1999.

Inicialmente foi adotado o modelo 1 que se segue:

(1) $\mathrm{PR}_{\mathrm{ijk}}=\mathrm{PV}_{\mathrm{ijk}}+\mathrm{Ano}_{\mathrm{j}}+\mathrm{Per}_{\mathrm{k}}+\mathrm{PV}_{\mathrm{ijk}} * \mathrm{Ano}_{\mathrm{j}}+\mathrm{PV}_{\mathrm{ijk}}$ * $\operatorname{Per}_{\mathrm{k}}+\mathrm{Ano}_{\mathrm{j}} * \mathrm{Per}_{\mathrm{k}}+\mathrm{PV}_{\mathrm{ijk}} * \mathrm{Ano}_{\mathrm{j}} * \mathrm{Per}_{\mathrm{k}}+\varepsilon_{\mathrm{ijk}}$, em que:

$\mathrm{PR}_{\mathrm{ijk}}$ refere-se ao preço final (R\$) por $\beta$ de peso vivo do i-ésimo lote, no j-ésimo ano de avaliação e k-ésimo período; $\mathrm{PV}_{\mathrm{ijk}}$ significa o peso vivo médio do i-ésimo lote, no j-ésimo ano de avaliação e k-ésimo período; $\mathrm{Ano}_{\mathrm{j}}$ refere-se ao ano de observação, em que $\mathrm{j}=2004,2005 \mathrm{ou}$
2006; e Per $_{k}$ refere-se ao período observado, onde $\mathrm{k}=$ outono ou primavera, além das interações das variáveis; e $\varepsilon_{\mathrm{ijk}}$ refere-se ao erro experimental observado para o i-ésimo lote, no jésimo ano de avaliação e k-ésimo período.

Como as interações deste modelo foram significativas $(\mathrm{P}<0,0001)$, foram testados modelos de regressão das variáveis peso vivo e preço final dentro de cada ano e período. Foi adotado o modelo de regressão linear, pois a utilização de modelos mais complexos (cúbico ou quadrático) não representou variações expressivas na significância do modelo e no coeficiente de determinação.

Assim, o modelo de regressão utilizado para cada período (primavera e outono) dentro de cada ano foi o que se segue:

(2) $\mathrm{PR}_{\mathrm{ijk}}=\mathrm{a} \pm \mathrm{b} * \mathrm{PV}_{\mathrm{ijk}}$, em que:

$\mathrm{PR}_{\mathrm{ijk}}$ refere-se ao preço final (R\$) por $\beta$ de peso vivo do i-ésimo lote, no j-ésimo ano de avaliação e k-ésimo período; $\mathrm{a}=$ valor do intercepto; $\mathrm{b}=$ coeficiente de regressão.

Os coeficientes de regressão foram comparados por meio de contrastes ortogonais com base na análise de covariância com efeito de ano, período, interação ano versus período e covariável linear de peso aninhado na interação ano versus período. Com base nas equações de regressão obtidas para os períodos analisados, foram realizadas simulações da variação no preço por $\beta$ de peso vivo, preço por bezerro e valorização obtida em resposta ao aumento de $30 \mathrm{~kg}$ de peso (de 150 para $180 \mathrm{~kg}$ ) nos bezerros comercializados em períodos de baixo ou alto preço de venda.

\section{RESULTADOS E DISCUSSÃO}

O peso vivo foi determinante do preço final dos bezerros comercializados em leilões (Fig. 1 e 2). Sua influência foi maior na primavera do que no outono, podendo considerá-lo como fator adicional na formação do preço de bezerros de corte comercializados na primavera, quando outras características dos animais também influenciaram na remuneração obtida, conforme explicaram Christofari et al. (2008). 


\section{Christofari et al.}

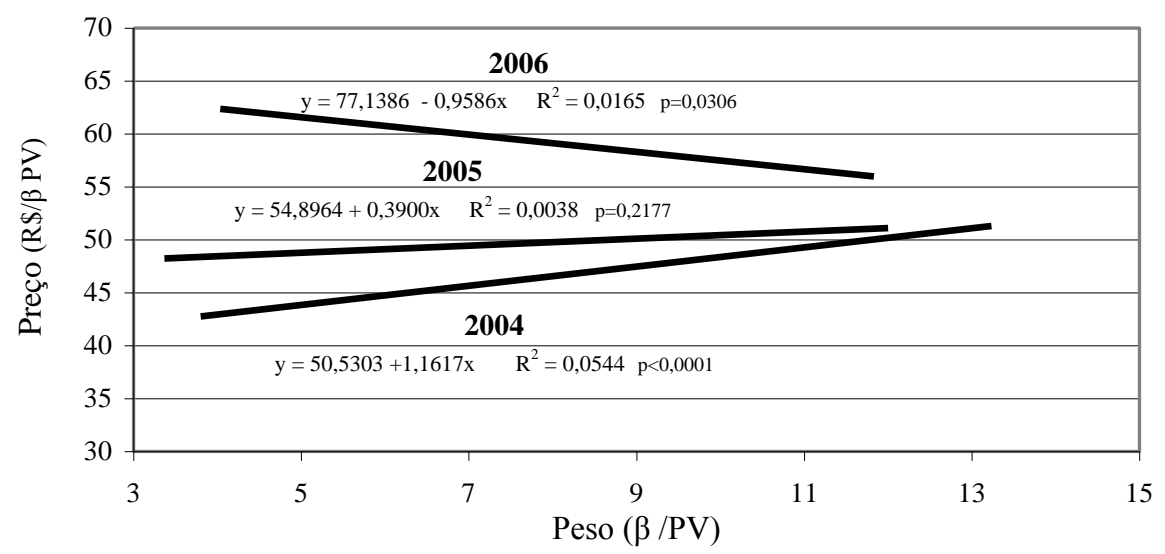

Figura 1. Regressão do preço ( $\mathrm{R} \$$ / $\beta$ PV) sobre a média de peso dos lotes de bezerros comercializados em leilões de outono nos anos de 2004, 2005 e 2006.

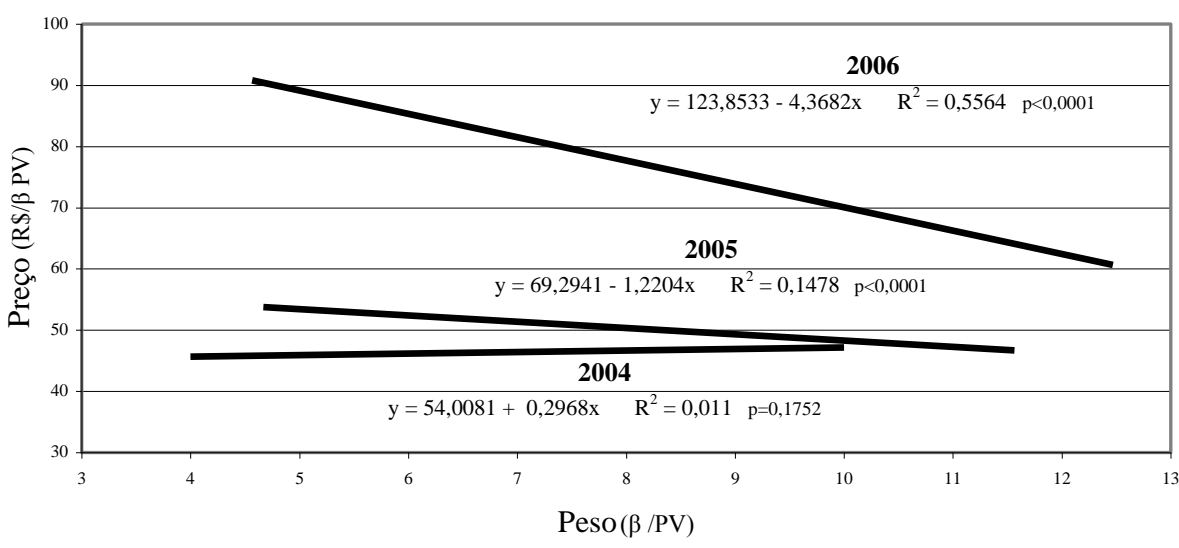

Figura 2. Regressão do preço (R $\$$ / $\beta$ PV) sobre a média do peso dos lotes de bezerros comercializados em leilões de primavera nos anos de 2004, 2005 e 2006.

O preço por unidade de peso variou ao longo dos anos, resultado da relação entre a oferta e a demanda dos bezerros no mercado. Além disso, o preço dessa categoria ainda é influenciado pelo preço de outras categorias animais, como, por exemplo, o boi para abate, pois são bens complementares (Eaton e Eaton, 1999), ou seja, não é viável abater um boi se não se adquirir ou produzir um bezerro. Em outros países, onde o sistema de produção é mais dependente da alimentação com grãos, as estimativas dos preços de culturas, como soja e milho, exercem forte influência nos preços de bezerros, de animais para recria e de confinamento (Dhuyvetter e Schroeder, 2000).
Para os anos de 2004 e 2005, os coeficientes de determinação foram baixos, indicando que $o$ peso vivo explicou muito pouco a variação do preço final por unidade de peso vivo dos animais avaliados. Nesses anos, havia grande quantidade de bezerros ofertados no mercado, o que possibilitou ao comprador considerar inúmeras características dos animais no momento da escolha por determinado lote em relação a outro.

Já em momentos de baixa oferta de animais e, consequentemente, de preços altos, como é o caso do ano de 2006, o peso vivo teve grande influência no preço final (R\$/ $\beta$ PV) (Fig. 2). 
Nestes períodos, em que não há muitos animais para a comercialização, o comprador reduz os critérios considerados para a escolha dos lotes desejados, pois existe o risco de não efetivar a compra pela grande demanda por animais ofertados. Além disso, ao adquirir animais mais leves, mesmo com um preço por unidade de peso mais elevado, o valor por animal é menor do que se comprasse animais mais pesados, o que possibilitaria ao comprador adquirir maior número de animais.

Quando se analisa a sequência dos períodos outono e primavera de 2004 , outono e primavera de 2005 e outono e primavera de 2006 - observase que há inversão na remuneração por unidade

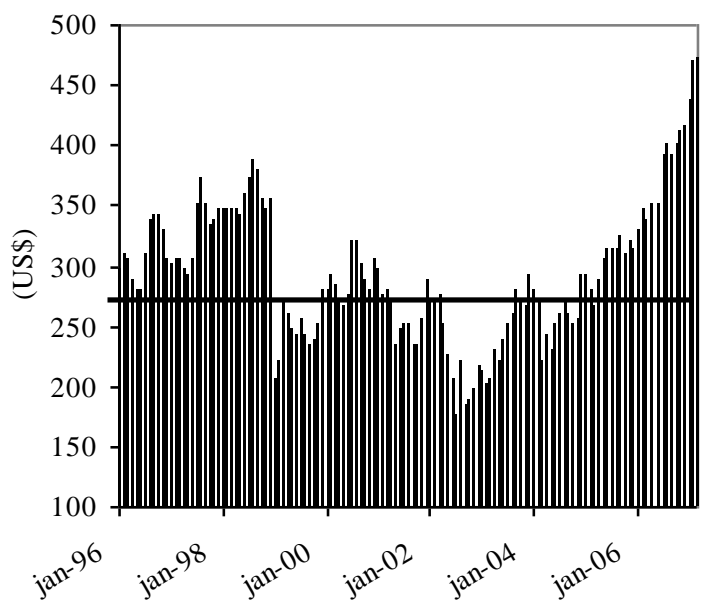

Boi para abate (US\$/animal) de peso, sendo que os coeficientes de regressão das equações foram significativos $(\mathrm{P}<0,05)$ para todos os períodos analisados, exceto para outono de 2004 e primavera de 2005. Inicialmente, em 2004, os animais mais pesados obtiveram um maior valor por $\beta$ de PV, passando por um período em que o peso praticamente não influenciou o preço, até o período em que a remuneração foi maior que a dos animais mais leves. Essa inversão pode estar relacionada ao ciclo de produção pecuário associada ao preço de venda de animais terminados (Fig. 3). Com baixos preços do boi para abate baixo, o pecuarista não terá estímulos para pagar mais pela reposição, reduzindo a demanda e forçando a queda do preço do bezerro.

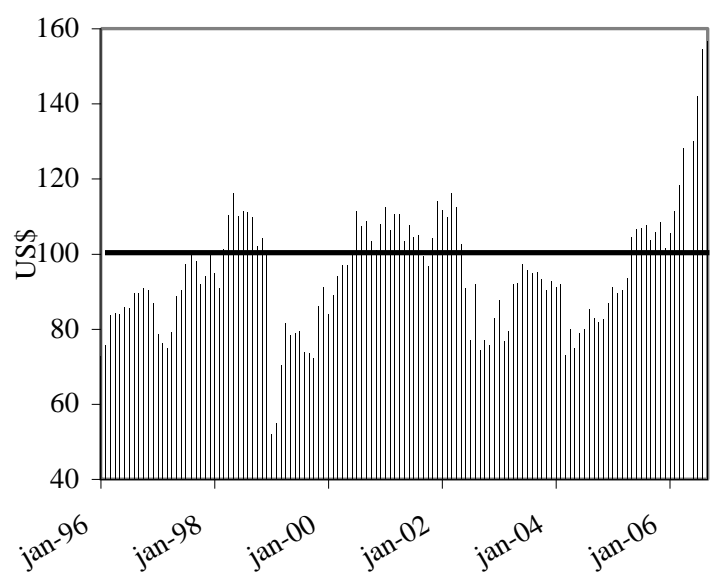

Bezerro (US\$/animal)

Figura 3. Preços de animais para abate (esquerda) e de bezerros (direita) praticados no Rio Grande do Sul nos últimos 10 anos (Fonte: EMATER/RS, 2007).

Isto é observado no ano de 2004, quando ocorreu tendência à aquisição de animais mais pesados coeficiente de correlação de 0,23 e 0,105 para os períodos de outono e primavera de 2004, respectivamente $(\mathrm{P}<0,05)$, reflexo da exigência de animais de maior peso ao abate destinados ao mercado externo - carcaças com 210 - 230kg -, o que, para sistemas de produção baseados em pastagens (naturais ou cultivadas), se torna mais rápido de atingir a partir de animais com peso mais elevado à desmama ou sobreano. Essa estratégia, além de atender às exigências do mercado consumidor (frigoríficos), aumenta a rotatividade de animais dentro do sistema, elevando o giro de capital em um período em que a margem de comercialização é muito pequena. Trabalhos semelhantes realizados por Sartwelle et al. (1996) e Smith et al. (2000) demonstraram relação inversa a este trabalho, ou seja, o preço por quilograma tendeu a diminuir com o aumento de peso vivo. Provavelmente, a menor oferta de animais mais pesados neste ano também contribui para a maior remuneração para esse tipo de animal.

A oferta de bezerros é reflexo de estímulos de alta ou baixa do preço, ou seja, preços altos estimulam a produção e vice-versa conforme afirmou Barros (1987). Além desse aspecto, a elevação do preço do boi gordo - 1999 e 2000, 
$2^{\circ}$ semestre de 2005 e 2006 (Fig. 3) -, possibilitou pagar mais pela reposição, o que estimulou a demanda e valorizou os preços, favorecendo a fase de cria e, consequentemente, aumentando a oferta nos anos seguintes. Esta alta oferta oriunda da cria fez com que os preços caíssem - 2002 a 2004 - desestimulando a produção de bezerros e forçando o produtor de bezerros a abater matrizes, para atender à demanda de recursos financeiros da atividade. Isto reduz o número de bezerros ofertados e torna a elevar os preços novamente, segundo Rosen et al. (1994). Esta queda na oferta refletiu-se na alta do preço do bezerro entre 2000 e 2001 e 2006 (Fig. 3), caracterizando o ciclo pecuário conforme mencionou Meyer (1997).

A ocorrência desses ciclos leva o comprador de bezerros a ter distintas posições frente às oscilações de mercado, pois, na maioria dos casos, a receita da qual se origina o capital para a aquisição de bezerros é proveniente da venda de animais para abate ou para recria. Assim, uma possibilidade de minimizar os efeitos do alto preço da reposição nos custos é a aquisição de animais mais leves, deixando pouco espaço para a escolha por outros atributos, como a qualidade dos animais, o que explica os coeficientes de correlação negativos entre o preço e o peso dos bezerros $-\mathrm{r}=-0,128$ e $-0,745$, para os períodos de outono e primavera de 2006, respectivamente $(\mathrm{P}<0,05)$.

A baixa padronização dos animais ofertados no Sul do Brasil possibilita flexibilizar os sistemas de recria e engorda, pois não existe um peso fixo para a categoria bezerro e são ofertados animais de todas as faixas de peso vivo, conforme demonstrado na Fig. 4, que apresenta a quantidade de animais ofertados nos períodos de outono e primavera, nos três anos avaliados.

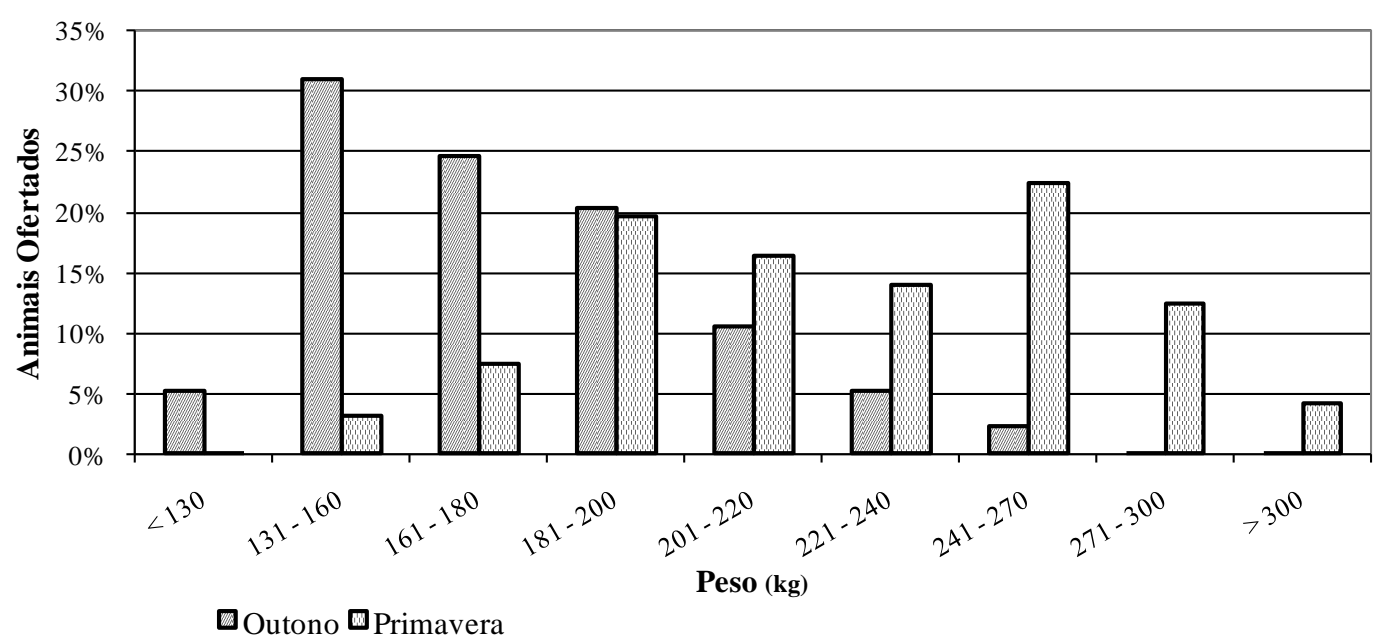

Figura 4. Média de pesos dos lotes de bezerros ofertados durante três anos de avaliação em leilões realizados no outono e na primavera.

Os animais comercializados no outono geralmente provêm de nascimentos da primavera anterior e chegam aos leilões com idades entre cinco a sete meses. $O$ peso de comercialização deles é semelhante ao de desmame, pois é realizado próximo ou no ato da venda. Sendo assim, o peso é fundamentalmente resultado da produção de leite da mãe (Barcellos e Lobato, 1992; Restle et al., 2004), que é determinada pelas condições alimentares disponíveis para essa categoria (Rovira, 1996).
$\mathrm{Na}$ primavera, os animais ofertados são, em grande parte, nascidos na primavera anterior e chegam aos leilões com 9 a 10 meses. Além disso, há outros bezerros provenientes de acasalamentos de outono, tornando a oferta de animais pesados mais alta neste período.

Nas Fig. 5 e 6, demonstra-se a liquidez dos diferentes lotes ofertados ao longo dos anos, no outono e na primavera. Nos dois primeiros anos, quando o mercado era desfavorável tanto para a cria quanto para a terminação, não foram 
comercializados 18,7 e $3,8 \%$ dos animais ofertados, respectivamente, para os anos de 2004 e 2005. Nesses anos, os animais mais leves, nas faixas de peso até $180 \mathrm{~kg}$, representaram cerca de $90 \%$ dos que não foram comercializados.

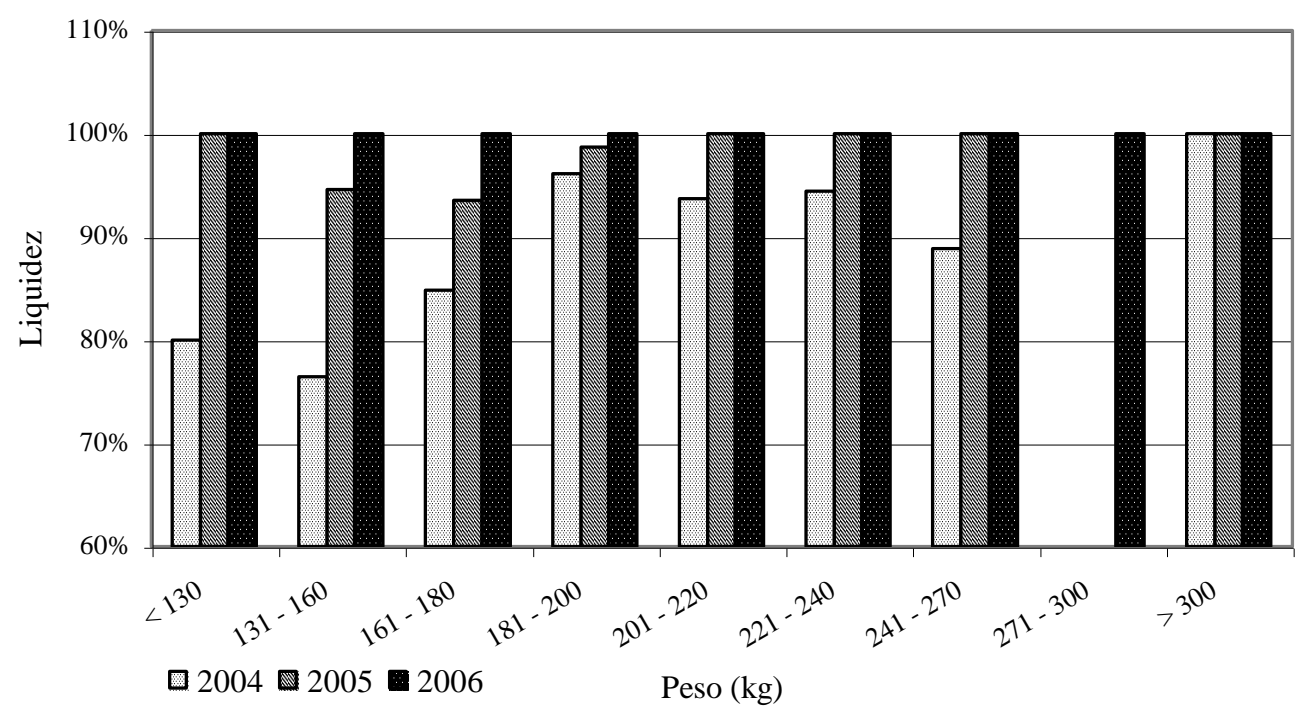

Figura 5. Liquidez dos lotes de bezerros ofertados no outono, nos três anos avaliados, conforme a média de peso vivo do lote.

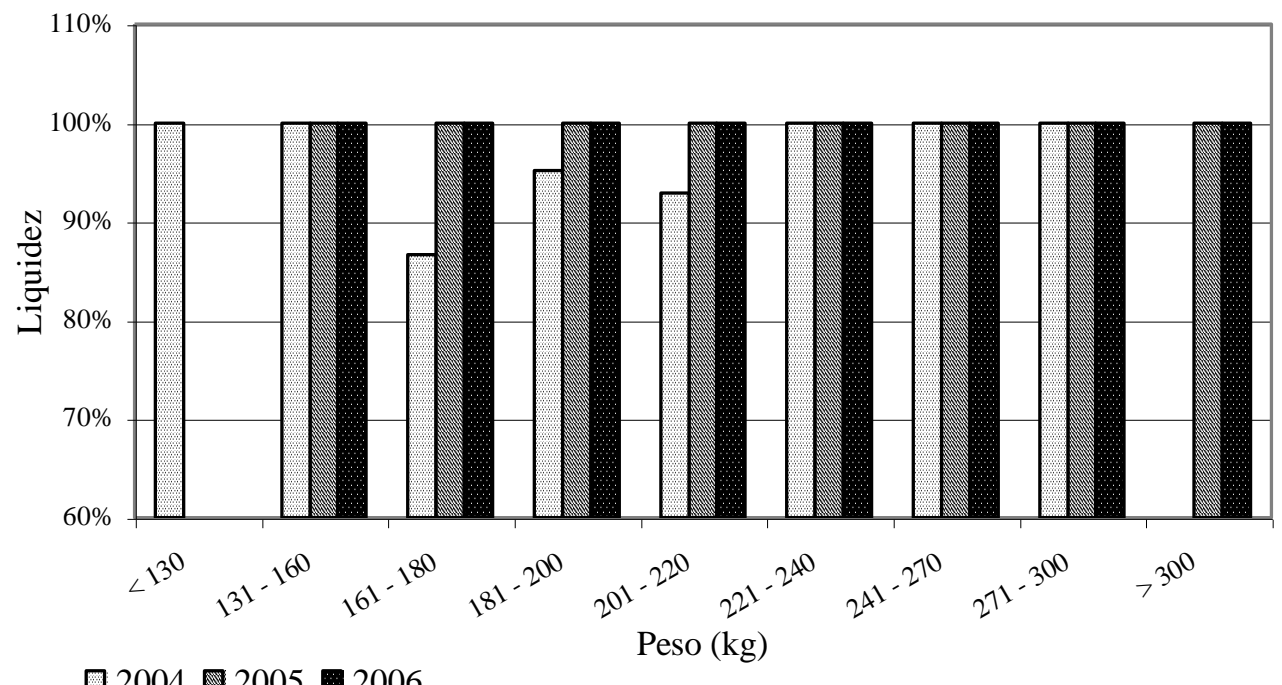

Figura 6. Liquidez dos lotes de bezerros ofertados na primavera, nos três anos avaliados, conforme a média de peso vivo do lote.

No final de 2005, a atividade de terminação já vinha obtendo melhores resultados econômicos, ao contrário do que acontecia com a atividade de cria (Fig. 3), que ainda atravessava momentos de preços extremamente baixos. Isto, aliado à grande oferta de bezerros no mercado, possibilitava ao comprador considerar outras características importantes no momento da compra dos animais, como, por exemplo, genética, sanidade, manejo e rastreabilidade 
(Christofari et al., 2007; 2008). Paralelamente, o mercado favorável para a terminação, que indicava previsão de maiores lucros futuros pela venda de animal terminado, fez com que o comprador buscasse animais mais leves, de menor valor unitário, mas maior em relação à unidade de peso (Fig. 2).

Dhuyvetter e Schroeder (2000) demonstraram que à medida que aumentam os preços futuros para bovinos confinados, animais mais leves são mais valorizados em relação aos mais pesados. Isto se acentuou em 2006, pois, além da previsão de lucros futuros, os preços de todas as categorias animais aumentaram em relação aos preços dos anos anteriores, como consequência de muitas variáveis, entre elas o intenso abate de fêmeas, que se refletiu na oferta de bezerros. A redução da oferta resultou em aumento de preço de reposição, fazendo com que os compradores preferissem animais mais leves em relação aos mais pesados, devido ao fato de adquirirem maior número de animais embora com baixo peso, pois o preço de animais para o abate estimulava a terminação de maior número de cabeças. A demanda por animais mais leves tem reflexos no preço desse tipo de animal, pois esses apresentam maior valorização em relação aos mais pesados. Sartwelle et al. (1996) e Smith et al. (2000) verificaram que aumentos no peso vivo dos bezerros levam a decréscimos no preço por unidade de peso.

Embora as análises apresentassem baixos coeficientes de regressão em alguns dos períodos analisados, eles podem auxiliar na tomada de decisões para introduzir tecnologias destinadas a aumentar o peso ao desmame. Pelo uso de contrastes ortogonais, foi avaliado o efeito do acréscimo de uma unidade $\beta$ (30kg PV) no peso do bezerro ofertado durante o período avaliado (outono de 2004 a primavera de 2006), sendo estimado um crescimento de $\mathrm{R} \$ 4,72$ no preço final $(\mathrm{P}<0,0001)$. Essa magnitude foi influenciada pela comparação entre intervalos menores; entre o outono e a primavera de 2006, o valor estimado foi de $\mathrm{R} \$ 3,00 / \beta(\mathrm{P}<0,0001)$. Por outro lado, entre a primavera de 2004 e o outono de 2005, o aumento de $30 \mathrm{~kg}$ no peso dos bezerros não influenciou o preço final $(\mathrm{P}<0,05)$.

Na Fig. 7, simulam-se as remunerações obtidas comparando a comercialização de um animal de $150 \mathrm{~kg}$ (base) e outro de $180 \mathrm{~kg}$ nos diferentes cenários de preços encontrados durante os anos avaliados.

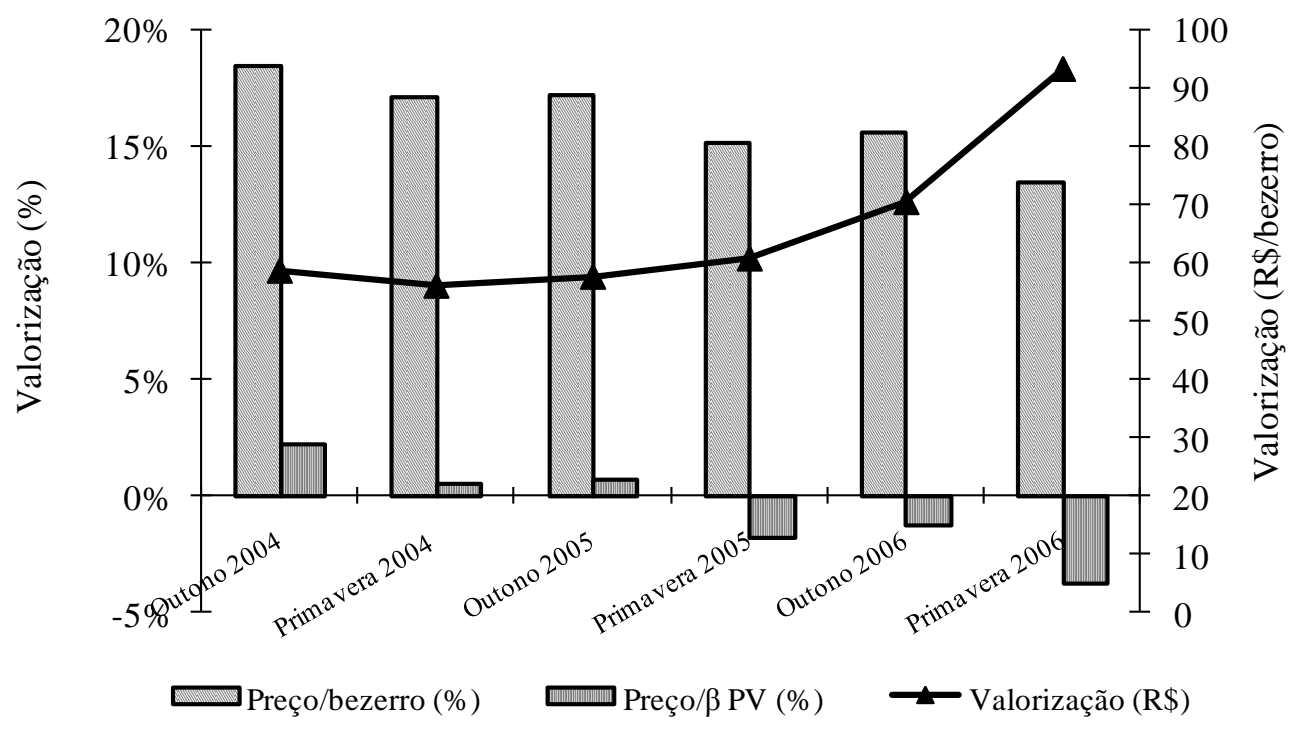

Figura 7. Valorizações por animal (\% e absoluta) e unidade de peso vivo simulando a diferença entre a comercialização de bezerros com $150 \mathrm{~kg}$ e $180 \mathrm{~kg}$ nas diferentes épocas avaliadas. 
A adição de $30 \mathrm{~kg}$ em um bezerro de $150 \mathrm{~kg}$ proporcionou uma valorização de aproximadamente $15 \%$ no preço final por animal, e uma desvalorização de $0,5 \%$ por $\beta$ de peso vivo, na média dos períodos avaliados. Contudo, quando se observaram preços de comercialização mais altos - 2006 -, o resultado dessa transação também foi maior do que em períodos de preços mais baixos (Fig. 7). Desse modo, se se considerar a primavera de 2006, mesmo com desvalorização de $3,5 \%$ no valor do preço por $\beta$ de peso vivo, um animal com $180 \mathrm{~kg}$ obtém, em valores absolutos, cerca de $\mathrm{R} \$ 90,00$ a mais do que um bezerro de $150 \mathrm{~kg}$.

Assim, as análises de mercado são fundamentais, pois em momentos em que há tendências de alta no preço, pode ser lucrativo investir em tecnologias de curto prazo, que proporcionem ganho de peso pré-desmama, mesmo que os valores por unidade de peso sejam menores para os animais mais pesados.

\section{CONCLUSÕES}

O peso vivo tem influência na compra e na venda de bezerros nos diferentes cenários de mercado, contudo, é apenas uma das variáveis que pode influenciar o preço final de bezerros. $\mathrm{O}$ maior impacto sobre o preço ocorre em situações de baixa oferta dessa categoria animal no mercado, sendo pouco expressivo quando a oferta passa a ser maior. Além disso, quando o objetivo é a comercialização de animais no outono, outros aspectos podem ter maior impacto do que simplesmente o peso vivo. Portanto, produzir animais de qualidade, com genética, sanidade e manejo adequado, auxiliado por ferramentas de mercado, como análises de tendências de preço, antes de introduzir tecnologias que aumentem o custo de produção dos sistemas de cria, pode melhorar a lucratividade na comercialização de bezerros.

\section{AGRADECIMENTOS}

Os autores agradecem ao CNPq pelas concessões das bolsas de Pós-Doutorado Júnior e Pesquisador II ao primeiro e segundo autor, respectivamente.

\section{REFERÊNCIAS BIBLIOGRÁFICAS}

BARCELLOS, J.O.J.; LOBATO, J.F.P. Efeitos da época de nascimento no desenvolvimento de bezerros Hereford e suas cruzas: I. Peso ao nascer e ganho médio diário a pré-desmama. Rev. Soc. Bras. Zootec., v.21, p.137-149, 1992.

BARROS, G.S.C. Economia da comercialização agrícola. 1.ed. Piracicaba: FEALQ. 1987. 306p.

CHRISTOFARI, L.F.; BARCELLOS, J.O.J.; AGUIAR, L.K. et al. Effects of changes in Brazilian beef traceability system on feeder steer trade. In: SYMPOSIUM INTERNATIONAL FOOD \& AGRIBUSINESS MANAGEMENT ASSOCIATION, 17., 2007, Parma, Italia. Proceedings... Parma: IFAMA, 2007 (CDROM).

CHRISTOFARI, L.F.; BARCELLOS, J.O.B.; COSTA, E.C. et al. Tendências na comercialização de bezerros no Rio Grande do Sul relacionadas às características genéticas. Rev . Bras. Zootec., v.37, p.171-176, 2008.

DHUYVETTER, K.C.; SCHROEDER, T.C. Price-weight relationships feeder cattle. Can. J. Agric. Econ., v.48, p.299-300, 2000.

EATON, B.C.; EATON, D.F. Microeconomia. 3.ed. São Paulo: Saraiva, 1999. 606p.

EMATER/RS. Preços agropecuários. Disponível em: <www.emater.tche.gov.rs>. Acessado em: 1 mar. 2007.

FUNDAÇÃO de Economia e Estatística - FEE. Atualização de valores. Disponível em: <http://www.fee.tche.br>. Acessado em: 10 jun. 2008.

MARQUES, P.V.; AGUIAR, D.R.D. Comercialização de produtos agrícolas. São Paulo: EDUSP, 1993. 295p.

McKISSICK, J.C.; BROWN, D.T. Profitable cattle marketing for the cow-calf producer. Athens, Ga: University of Georgia College of Agricultural and Environmental Sciences, 2001. 11p. (Bulletin 1078).

MEGIDO, J.L.T.; XAVIER, C. Marketing \& Agribusiness. 3.ed. São Paulo: Atlas, 1998. 334p. 
MEYER, L. Marketing beef cattle. In: THE KENTUCKY BEEF BOOK. Lexington, KY: University of Kentucky, College Agriculture, 1997. 127p. Disponível em: <www.uky.edu>. Acessado em: 5 ago. 2004.

POPP, M.P.; PARSCH, L.D. Marketing practices of Arkansas beef cattle producers. Fayetteville, Ark: University of Arkansas Agricultural Experiment Station Research, 1998. 41p. (Bulletin 957).

REIS, A.J. Comercialização agrícola no contexto agroindustrial. Lavras: UFLA, 1999. $358 \mathrm{p}$.

RESTLE, J.; PACHECO, P.S.; PASCOAL, L.L. et al. Efeito da produção e da composição do leite no desempenho de bezerros de diferentes grupos genéticos. Rev. Soc. Bras. Zootec., v.33, p.691-703, 2004.

ROSEN, S.; MURPHY, K.M.; SCHEINKMAN, J.A. Cattle cycles. J. Polit. Econ., v.102, p.468493, 1994.
ROVIRA, J. Manejo nutritivo de los rodeos de cría en pastoreo. Montevideo: Hemisferio Sur, 1996. 288p.

SANTOS, A.P.; BARCELLOS, J.O.J.; CHRISTOFARI, L.F. et al. Traceability as a competitive advantage in beef calves marketing. In: WORLD FOOD \& AGRIBUSINESS SYMPOSIUM, 16., 2006, Buenos Aires. Proceedings... Buenos Aires: IFAMA, 2006 (CD-ROM).

SARTWELLE, J.D.; MINTERT, J.R.; BRAZLE, F.K. et al. Improving the value of your calf crop: the impact of selected characteristics on calf prices. Manhattan, KS: State University Agricultural Experiment Station and Cooperative Extension Service, 1996. 12p. (MF - 2142).

SMITH, S.D.; GILL, D. R.; BESS, C. et al. Effect of selected characteristics on the sale price of feeder cattle in Eastern Oklahoma. Oklahoma, Okla: Oklahoma State University, 2000. 15p. (E-955). 